\title{
What drives the travel switching behavior of Chinese Generation Z consumers
}

\author{
Li-Yu Tseng, Jung-Hsiang Chang and Ying Lin Zhu
}

\begin{abstract}
Purpose - As Chinese Generation Z consumers have distrust over traditional advertising and marketing, this study focuses on user-generated content (UGC) travel apps to demonstrate the structural relationship among the expertise of amateur information publisher, interactive atmosphere, information quality, expectation confirmation, perceived trust, experiential satisfaction and switching intention.

Design/methodology/approach - This study carried out a questionnaire-based survey among Chinese Generation Z consumers and obtained 356 valid questionnaire copies that were analyzed with the structural equation.

Findings - The expertise of amateur information publisher and the interactive atmosphere of UGC travel apps have positive effects on perceived trust; expectation confirmation and perceived trust have positive effects on experiential satisfaction, and experiential satisfaction has negative effects on switching intention.

Practical implications - The results should encourage UGC travel app developers to use visual effects so as to achieve a higher quality of information, foster a cordial interactive atmosphere and enhance the expertise of information publishers by selecting the best candidate, thus spurring the design of marketing activities popular among the Chinese Generation Z consumers.

Originality/value - This study argues that new-generation consumers have their specific appeals and in the tourist market. It explores the UGC travel apps, which are popular among Generation Z consumers in order to deepen marketing personnel's understanding of the relationship among the expertise of amateur information publisher, interactive atmosphere, information quality, expectation confirmation, perceived trust, experiential satisfaction and switching intention.
\end{abstract}

Keywords Generation Z consumers, Expertise of information publisher, Interactive atmosphere, Information quality, Switching intention

Paper type Research paper

\section{Introduction}

The Chinese Generation Z (born 1995-2010) has a large population of 149 million. Living under a society shaped by China's only-child policy, this young generation, particularly born from 1995 to 2010, has shown impressive consuming power even though they are financially supported by their parents and relatives. It is forecasted that they will account for $40 \%$ of the entire country's consuming power by the end of 2020 (Kantar and Tencent, 2018). They desire a more wonderful life and are thus willing to spend more time and money in seeking pleasure and believe that travel is the most important thing in their lives (Skift, 2017). Therefore, analyzing these new consumers in this study on the tourist market is meaningful and timely. Generation Z regards travel apps as the main sources of tourist information and itineraries (Rezdy, 2018). There is a wide variety of such apps in China that are easy to access and uninstall. The Generation Z consumers spend an extremely short time to keep attention on the brands, even as short as eight seconds, which is $50 \%$ shorter than that found among the Millennials (Shatto and Erwin, 2016). Hence, it is great research value to probe into the factors that reduce the switching intention on UGC travel apps for Generation Z, especially this Generation Z who exhibit an extremely low loyalty.
$\mathrm{Li}-\mathrm{Yu}$ Tseng is based at the Business School, Nanfang College of Sun Yat-sen University, Guangzhou, China.

Jung-Hsiang Chang is based at the Accounting School, Nanfang College of Sun Yat-sen University, Guangzhou, China. Ying Lin Zhu is based at the Business School, Nanfang College of Sun Yat-sen University, Guangzhou, China.

\author{
Received 21 July 2020 \\ Revised 6 March 2021 \\ 19 May 2021 \\ Accepted 24 June 2021
}

(C) Li-Yu Tseng, Jung-Hsiang Chang and Ying Lin Zhu.

Published in Journal of Tourism Futures. Published by Emerald Publishing Limited. This article is published under the Creative Commons Attribution (CC BY 4.0) licence. Anyone may reproduce, distribute, translate and create derivative works of this article (for both commercial and non-commercial purposes), subject to full attribution to the original publication and authors. The full terms of this licence may be seen at http://

creativecommons.org/licences/ by/4.0/legalcode 
Generation $Z$ is greatly affected by the technology products, such as the internet, instant messaging, text messaging, MP3 players, mobile phones, smartphones and tablet computers. They can be said to be the first generations who have lived in both the virtual and real worlds (Skift, 2017). They are interested in new technology than their predecessors (Generation $X$ and $Y$ ) and rely more on mobile phones, tablets for their social life. This situation has also changed the opinion of time and place in consumption habits (Özkan, 2017). This also encourages companies to integrate social media marketing into their marketing portfolio tools, not only to communicate with consumers, but also to obtain feedback (Karamian et al., 2015). In social media marketing, usergenerated content (UGC) is the most popular. It is the content created by non-professionals and uploaded to the internet (Assaker, 2020). Compared with traditional marketing tools, UGC is less business interests and is more trustworthy with the information of the real consumer experience. It shows the travelers are increasingly relying on UGC websites and travel review platforms to help them collect information and make travel decisions (Ayeh et al., 2016).

Furthermore, according to the findings of Kim and Kim (2017), online consumers tend to be influenced by the massive amounts of text and visual and multimedia materials on the internet, such as pictures, videos and comments, and the interactive atmosphere they feel in online tourist communities reduces their perception of relevant uncertainties and risks (Park et al., 2016), thus helping to develop their trust in online or virtual tourist communities. Veríssimo and Costa (2018) demonstrated that properly designed interactive activities or a positive interaction between consumers and waiters/waitresses in hotels increase consumer satisfaction. Laumer et al. (2017) pointed out that information quality has positive effects on user satisfaction. Joo and Choi (2016) suggested that consumers' expectation confirmation and information quality can affect their satisfaction. Liang et al. (2018) proposed that consumers' trust and satisfaction have negative effects on their switching intention.

Therefore, this research mainly discusses (1) the amateur publishers of the travel apps have their expertise, can provide consumers with reliable information on travel destinations (for example, what are the attractions worth visiting, what products are worth buying, suggest how many days to stay in the destination... etc.) and control the quality of the information, so that consumers can clearly feel that the information quality of the app is better than other travel apps, and also they are willing to create a good interactive atmosphere, can it increase consumers' perceived trust and experience satisfaction; (2) When users use the travel information of the UGC travel app to make their expectations before travel and their feelings after travel consistent, whether the user's experience satisfaction with the UGC travel app can be improved; (3) Whether the user's perceived trust can increase the user's experience satisfaction with the UGC travel app and reduce the willingness to switch to other UGC travel app; (4) When increasing the user's experience satisfaction with the UGC travel app can also reduce consumer conversion the idea of UGC travel app.

Although a change to the population has direct or indirect effects on tourism, recent studies on the Generation Z have focused on market surveys that cover effective marketing and advertising, with just a few of them in the academic literature (Robinson and Schänzel, 2019). For instance, Corbisiero and Ruspini (2018) discussed the challenges and prospects that the Millennials and the Generation $Z$ bring to international tourism. This may be caused by the fact that the oldest members of the Generation $Z$ are in their early adulthood and can travel all by themselves, without the companionship of or consent from their parents. Other studies have explored the effects of social media, reputation, travel plan and other specific factors on tourists' purchase and decisionmaking procedure (Pinto et al., 2015; Xiang et al., 2015). In order to make up for the deficiencies of academic research, this research summarized the market survey data and found that Generation Z consumers have characteristics such as UGC content that general consumers share, interact with others on social media and do not easily believe in commercial advertisements for discussion. Moreover, consumers think that those travel experiences shared in earnest by other tourists are actually reliable. In particular, information publishers that have expertise on tourist destinations win much trust from those in favor of the UGC model (Ukpabi and Karjaluoto, 2018). Consumers

PAGE 2 | JOURNAL OF TOURISM FUTURES $\mid$ VOL. $\mathbf{m} \mathbf{m}$ NO. $\mathbf{m} 2021$ 
become more satisfied with the services from social and commercial websites whose information publishers have abundant expertise (Filieri et al., 2017).

Previous studies have placed great focus on such issues as the expertise of information publisher, interaction atmosphere, information quality, trust, satisfaction, expectation confirmation and switching intention, but few have discussed UGC travel apps or generation-oriented marketing. Jin and Phua (2016) showed that the UGC model is a reliable and powerful marketing tool as well as a travel model favored by the Generation Z consumers (Rezdy, 2018). Therefore, combining UGC travel apps with travel marketing from the perspective of these consumers is a worthwhile research topic. This study thus integrates the UGC model with travel marketing and the pattern of switching intention. From the angle of the Generation Z consumers, it sets forth six factors - the expertise of amateur information publisher, interactive atmosphere, information quality, perceived trust, experiential satisfaction and expectation confirmation - and combines them in a travel marketing model with the goal of helping enterprises reduce the switching intention of the Generation Z consumers.

\section{Literature review and hypothesis development}

\subsection{The positive effects of expertise of amateur information publisher and perceived interactive atmosphere on perceived trust}

Many online retailers provide consumers with opportunities to share their experiences with other online consumers on social media (Bahtar and Muda, 2016), which is UGC. Contrary to content produced by producers who usually hire speakers and celebrities to talk about product advantages and benefits (Verhellen et al., 2013), shared content in UGC is based on consumer experience. They believe that users have no commercial interest (Mir and Rehman, 2013). Therefore, online consumers can rely on the UGC to help them make purchasing decisions (Bae and Lee, 2011). In terms of travel, UGC has become an important part of travel planning because travelers will evaluate travel products based on past reviews (Ukpabi and Karjaluoto, 2018). Among them, the professional knowledge of the publisher is most concerned by young consumers (Assaker, 2020).

Expertise of information publisher refers to the ability of an information publisher to provide persuasive information and argument (Hovland et al., 1953) and enable information recipients to perceive that the information is accurate and specialized (Netemeyer et al., 1992). It can be used to measure how much the information publisher knows about a specific thing or realm (Goldsmith et al., 2000). The Generation Z consumers live most of their day in cyber space (Özkan, 2017). As it is difficult for them to tell authentic information from fake news in the face of ever-changing messages, they are more likely to consult those with rich experience (Wavemaker, 2017) and place more trust on the opinions of amateur tourists in the UGC model in regard to tourism. Against this backdrop, this study puts forth a new concept - Expertise of Amateur Information Publisher - and defines it as a non-professional tourist worker who has travel experience in a tourist destination and understands travel needs (e.g. specialty snacks, Famous attractions, hotel recommendations, etc.). They also provide travel advice and preventive measures based on different local life experiences, help Generation Z consumers to make appropriate travel plans and make travelers believe that the travel information they release is accurate and professional (Netemeyer et al., 1992; Goldsmith et al., 2000).

Trust is an important antecedent of behaviors that demonstrate dependence on others, such as accepting others' advice (McKnight et al., 2002). Researchers have suggested that in the early stages of computer use, the trust may be related more to a consumer's perception of the technology itself. However, the building and sustaining of long-term trust is more complicated and based in part on the experiences that consumers have within virtual environments. According to scholars, online trust may be significantly influenced by the quantity and quality of information garnered during online experiences (Shankar et al., 2002). In other words, when consumers are shopping online, then they tend to place trust on the shopping experience of others when they

VOL. $\mathbf{m}$ NO. $\mathbf{m} 2021 \mid$ JOURNAL OF TOURISM FUTURES $\mid$ PAGE 3 
regard others' oral or written statements as reliable (Gefen et al., 2003). Relatively speaking, if consumers obtain correct and effective travel information on a travel app for a long time, they will also tend to trust the platform. Therefore, this study defines perceived trust as follows: the Generation Z consumers, when browsing UGC travel apps, regard the tourist information, products and services by apps users as reliable and tend to place trust on their tourist experience (Shankar et al., 2002; Gefen et al., 2003).

Scholars believe that consumers' trust in agents (sellers) may be partly affected by the agents' persuasiveness and communication results (Bart et al., 2005). Since consumers rely on online providers and their employees to provide accurate information during online transactions, the credibility or expertise of information agents may affect the level of trust among agents (Banerjee et al., 2017). It can be seen that when Generation Z consumers understand that the UGC travel information and itinerary plans on the travel application are in line with local conditions, they can feel the publisher's expertise and capabilities, so they believe that publishers can provide accurate information. Accordingly, the first hypothesis is proposed.

H1. The expertise of an amateur information publisher has a positive influence on perceived trust.

Generation Z not only loves to pursue self but also eager to get a sense of connection from the community (Rezdy, 2018). Therefore, exploring the interactive atmosphere has significance. Chen et al. (2018) defined interactive atmosphere as an interactive and communicative atmosphere among the members of a community. Frequent interaction in a community leads to a pleasant and interesting interactive atmosphere, where the members can access suggestions, exchange ideas, express their thoughts and even receive care from others and other forms of social assistance. To find out if the Generation Z consumers expect a good interactive atmosphere in an app community when using UGC travel apps, this study sets forth a new concept, perceived interactive atmosphere, cites the argument of Chen et al. (2018), defines it as "the pleasant atmosphere the Generation Z consumers feel in the interaction among the members of the virtual communities of UGC travel Apps who communicate with pictures, text, and emoji" and argues that the atmosphere encourages users to access suggestions and express views. Park et al. (2016) posited that if online community members foster a positive interactive atmosphere and feel the kindness of each other, then they will place more trust on the website and other members. Shan and $\mathrm{Lu}$ (2010) also argued that interactive atmosphere has significant positive effects on perceived trust in a community. As a result, the next hypothesis arises.

H2. Perceived interactive atmosphere has a positive influence on perceived trust.

\subsection{The positive effects of expertise of amateur information publisher, perceived interactive atmosphere, perceived information quality, expectation confirmation and perceived trust on experiential satisfaction}

Generation Z has a high degree of social media behavior, and it needs to combine social media behavior with other consumer information to form a consumer experience in social network (Skift, 2017). Experiential satisfaction derives from expanding the concept of service satisfaction to the scenario-specific service satisfaction and consumer emotion (Kao et al., 2008), and from an experiential perspective, it reflects satisfaction with the services related to some transactions $\mathrm{Wu}$ et al. , 2018a, b). Consumers make a comparison between their experience and expectation, which then results in positive or negative responses (Kao et al., 2008). Such emotional responses become the foundation of consumers' satisfaction or dissatisfaction. That is, when travelers adopt the recommendations of the expertise of amateur information publisher to design their itinerary, and when they find that this itinerary reduces their uncertainty in the journey, they will be satisfied with the travel app. On the basis of the above definitions, this study defines experience satisfaction, because amateur information publisher provide real travel information, so Generation Z travelers are satisfied with using UGC travel apps (e.g. Kao et al., 2008; Wu et al., 2018a, b). Kimetal. (2017) 
and Izogo (2016) probed into offline services and found that if consumers feel that a service supplier is highly professional, then they feel more satisfied. Filieri et al. (2017) explored the purchase intention on social and commercial websites and noticed that if an information publisher has rich expertise, then consumers feel more satisfied with the service. Therefore, the third hypothesis appears.

H3. The expertise of an amateur information publisher has a positive influence on experiential satisfaction.

Yang (2017) adopted key events to probe into the interactions among users of virtual brand communities and found that the interactive atmosphere is a primary factor that satisfies community members. Wu and Xiao (2017) showed that high-frequency interaction could facilitate communication among users, deepen mutual understanding and contribute to better user experience satisfaction. Moreover, Wang and Li (2015), in their study on the effects of UGC interaction on user brand attitude also demonstrated that user satisfaction increases with a stronger sense of information-based interactive atmosphere. Accordingly, we propose the following.

H4. Perceived interactive atmosphere has a positive influence on experiential satisfaction.

Generation $Z$ are accustomed to self-learning through the internet and are willing to create opportunities for online communication. They hope to quickly grasp information and effectively screen their concern. This shows that Generation Z pays attention to content quality and has a high degree of repetitive search and trust in information sources. Therefore, this study explores the necessity of information quality. According to Turban and Gehrke (2000), if a website offers highquality information, then it will be able to retain its online consumers, and it is also a main reason why consumers continue to use it (McKinney et al., 2002). Uotila and Melkas (2008) defined information quality as users' perception of the information by information systems and believed that its fundamental factors include readability, completeness, reliability and trustworthiness (Wilkinson et al., 1997). To find out if the Generation Z consumers expect a high information quality when using UGC travel apps, this study put forth a new concept, perceived information quality and cited the argument of the above scholars to define it as "the Generation Z consumers believe that the information on a website is true, reliable, easy to understand, pragmatic, and helpful for making a travel itinerary." Szymanski and Hise (2000) found that the quality of the information about products on websites is an effective index of predicting consumer satisfaction in online shopping; if a website offers users the information they want, then they will feel more satisfied with the website (Almahamid et al., 2010), Accordingly, the following hypothesis is presented.

H5. Perceived information quality has a positive influence on experiential satisfaction.

In his exploration into the antecedents and follow-up behaviors of user satisfaction, Oliver (1980) proposed the expectation-confirmation theory. Bhattacherjee (2001) defined expectation confirmation as the results of a comparison between the actual effects of products or services perceived by users and user expectation. For a UGC travel app, if the actual effects of the information system as perceived by users are greater than their expectation, then there will be a high degree of expectation confirmation; otherwise, there will be a perception imbalance and a low degree of expectation confirmation. Therefore, this study defines expectation confirmation as "the degree of consistency between the actual effects of a travel App perceived by the Generation Z consumers and their expectation."

Information quality is a main prediction index of expectation confirmation (Chiu et al., 2005). Some scholars studied user satisfaction with the knowledge intensity network (Koo et al., 2011) and the e-learning system (Cheng, 2014) in the National Cancer Information Center. They all demonstrated that if the information quality of the systems as perceived by users is higher than their expectation, then they will develop a positive attitude toward the systems. Hsu and Lin (2015) adopted an expectation confirmation model to probe into a mobile payment app and concluded that 
expectation confirmation has positive effects on user satisfaction. Accordingly, we have two more hypotheses.

H6. Perceived information quality has a positive influence on expectation confirmation.

$H 7$. Expectation confirmation has a positive influence on experiential satisfaction.

Kim and Ahmad (2013) believe that the reliability of system operators plays an important role in online social media. They believe that if a new system provides low-quality information in the market and causes consumer distrust, it will reduce user satisfaction (Akter et al. , 2013). Bricci et al. (2016) describe that trust has a positive and direct effect on satisfaction. Khalilullah (2013) proposes that trust plays a crucial role in influencing satisfaction in the banking industry. Accordingly, the following hypothesis is proposed.

H8. Perceived trust has a positive influence on experiential satisfaction.

\subsection{The negative effect of perceived trust and experiential satisfaction on switching intentions}

Generation Z is a group of low loyalty and discussing the switching intention has become a very important issue. Switching intention refers to the psychological tendency that consumers try to suspend the use of current products or services and choose other similar products or services (Keaveney, 1995). In other words, users make a negative assessment of current products or services and thus may develop a negative behavioral tendency (Zeithaml et al., 1996) and even want to terminate the current transaction with a relevant enterprise (Bansal et al., 2005). When consumers find that travel apps provide too much untrue information about travel destinations, such as asking key opinion leaders to make commercial tweets for advertising revenue, hotels or itineraries introduced are inconsistent with the content of the tweets, etc., they will want to stop using or switch to other travel apps. Building on this, this study defines switching intention as "the Generation Z consumers intend to stop using a current UGC travel app and shift attention to a new one that provides similar contents or services."

Doney and Cannon (1997) explored the online shopping decision-making of consumers and found that if they trust an online store, then the enterprise operating the store could develop a long-term relationship with them and thus reduce their switching intention. Bedford (2005) also proposed that once users lose trust in a piece of mobile software, they lower their frequency of using it or even stop using it. Therefore, we have the next hypothesis.

H9. Perceived trust has a negative influence on switching intention.

Lee et al. (2011) studied the user switching behaviors in virtual communities and also demonstrated that satisfaction has negative effects on switching intention. Li et al. (2007) found that satisfaction is the most critical discriminant factor that influences college students switching to alternative websites. So the relationship of the satisfaction and intention provides the basic marketing/service concept to the service operations that are required to satisfy the customer need and desire to prevent switching (Kotler et al., 2003). As a result, the last hypothesis runs as follows.

H10. Experiential satisfaction has a negative influence on switching intention.

\section{Research methodology}

\subsection{The measures}

This study adopted the measurement items from previous studies and all scales include multiple items. First, the measurement of expertise of amateur information publisher comprises four items modified from the study of Netemeyer et al. (1992). Second, the measurement of perceived interactive atmosphere includes three items used in the research of Chen et al. (2018). Third, the 
measurement of Perceived Trust includes four items used in the research of Mayer et al. (1995) and McKnight et al. (2002). Fourth, the measurement of experiential satisfaction comprises three items modified from the research of Wu et al. (2018a, b). Fifth, the measurement of Perceived Information Quality includes four items adopted from the study of Uotila and Melkas (2008). Sixth, the measurement of expectation confirmation comprises three items modified from the study of Bhattacherjee (2001). Finally, the measurement of switching intentions comprises three items adopted from the research of Bansal et al. (2005). In total, 24 measurement items for the seven constructs shown in Table 1 were measured using a seven-point Likert scale ranging from 1 (strongly disagree) to 7 (strongly agree). Measurement model and confirmatory factor analysis are presented as follows:

Confirmatory factor analysis (CFA) was conducted to examine the validity by applying LISREL 8.7. According to Brown (2006), CFA is often the analytic tool of option for developing and refining measurement method, assessing construct reliability (CR) and validity, identifying method effects and evaluating factor invariance across time and groups. First, the CFA results are introduced in Table 1. In terms of reliability and validity, according to scholars' arguments, a CR value equal to or greater than 0.7 indicates good reliability (Churchill, 1979; Hair et al., 1998). The CR value of this study ranges from 0.749 to 0.821 , indicating that the measurement structure is good. Cronbach's $\alpha$ is the other measure of reliability. Cronbach's $\alpha$ coefficient for all constructs ranged between 0.726 and 0.818 . All the coefficients were more than 0.70 , indicating an adequate level of reliability (Nunnally, 1978). Subsequently, this paper applied the standardized factor loadings and average

Table 1 Confirmatory factor analysis: items and loadings

Item

1. Expertise of amateur information publisher: construct reliability $(C R)=0.796$, average variance extracted $(A V E)=0.619$,

Cronbach's alpha $(\alpha)=0.794$

The amateur information publisher is familiar with the relevant information of the tourist attraction

The amateur information publisher is experienced in the tourism field

The amateur information publisher is capable in the tourism field

0.832

The amateur information publisher is very professional in the tourism field

2. Experiential satisfaction: $C R=0.813, A V E=0.733, \alpha=0.818$

I Am satisfied with my decision to use this travel app

The travel App meets my needs for the travel information content

0.847

I Think I did the right thing by using this travel app

3. Perceived interactive atmosphere: $C R=0.768, A V E=0.527, \alpha=0.726$

When using the travel app, I feel that users can exchange different views and opinions

0.829

When using the travel app, I feel that communication between users is easy and enjoyable

When using the travel app, I feel that certain content (videos, pictures, text, etc.) posted by users is interesting

4. Perceived trust: $C R=0.821, A V E=0.647, \alpha=0.818$

I Trust the travel information provided by the travel app

I Believe that the travel information provided by the travel app is not much different from the actual experience

0.790

I Think the travel itinerary provided by the travel app is the right choice

0.854

I Believe it is safe to purchase the travel itinerary provided by the travel app

5. Perceived information quality: $C R=0.749, A V E=0.591, \alpha=0.770$

I Believe I can trust the information provided by the user in this travel app

I Think the information provided by users in this travel app is clear and easy to understand

0.738

I Think the information provided by the user in this travel app is useful and easy to retrieve quickly

0.796

I Think the information provided by the user in this travel app is beneficial to me and helps to formulate a travel itinerary

6. Expectation confirmation: $C R=0.785, A V E=0.696, \alpha=0.783$

The travel information provided by users in this travel app is better than I expected 0.847

The overall experience when using this travel app is better than I expected 0.857

Overall, most of my expectations were met during using this travel app 0.799

7. Switching intentions: $C R=0.816$, AVE $=0.726, \alpha=0.812$

I Am considering switching from this travel app and using other travel apps instead 0.844

My likelihood of switching from this travel app to another one is high

Recently, when formulating a travel itinerary, I rarely use a previous travel app and more often use a new travel app 0.823

Note(s): All factor loadings are significant at $p<0.001$ 
variance extracted (AVE) of each construct to verify the convergent validity. For each construct, the standardized factor loading was above the threshold of 0.5 , as suggested by Bagozzi and Yi (1988) and the AVE was higher than the threshold of 0.5, as suggested by Hair et al. (1998). So it means that $50 \%$ of the variance of the measurement items can be accounted by latent variables, which means that the convergence validity of this study is good (Table 1).

In this study, the results of the chi-square difference test revealed that the statistical value of the chi-square difference between the constructs was significant $\left(\chi^{2} / \mathrm{df}=2.22, p<0.001\right.$, RMSEA $=0.059, \mathrm{GFI}=0.88, \mathrm{AGFI}=0.87, \mathrm{IFI}=0.97, \mathrm{SRMR}=0.075)$. The before-mentioned results proved that the correlation coefficients between the constructs were not equal to one. Thus, the constructs of the research model in this study had discriminant validity. Alternatively, discriminant validity is established if the shared variance is larger than the squared correlations between constructs (Fornell and Larcker, 1981). All 7 pairs of squared correlations were smaller than the shared variance of the respective constructs. The results for the measurement model are shown in Table 2. Accordingly, the data recommend that strong evidence of construct validity and reliability are present in terms of the conceptual research model.

\subsection{Data collection and the sample}

At present, the age group of Generation $Z$ is between 11 and 25 years old. As the traveler between 11 and 17 years old must be accompanied by a legal agent, parents will not allow them to travel alone with other friends. Furthermore, as 15-17 years old are in the senior high school stage. In China, they are under great pressure to enter a college/university. Most of them choose to live on campus and usually do not consider traveling with friends during this period. Therefore, this study selects consumers who can travel autonomously without a guardian as the age group of 18-25 years old (Skift, 2017). A questionnaire survey was conducted to validate the hypotheses and research framework.

In the pre-test of this research, first, six experts and scholars were invited to modify the questionnaire to ensure that the content of the questionnaire was designed to meet the scholar's opinion, and there was no semantic change due to the change from English to Chinese. Second, randomly find 40 students who answer have used UGC Travel apps before in the Nanfang College of Sun Yat-Sen University in Guangzhou (because the current college students are between 18-22 years old, they belong to the Generation Z). We ask them to read and fill out the questionnaire and again to determine whether the terms, meanings and questions were ambiguous, and to modify the question items. Therefore, the questionnaire in this study has high content validity.

In the formal questionnaire survey, dated from November 25, 2019, to January 10, 2020, random samples were selected at the Guangzhou Higher Education Super Center, it is because the Guangzhou Higher Education Super Center is the concentration of all universities and research institutes in Guangzhou, in there the students belong to the 18-25 year-old Generation Z, and many of its staff belong to the Generation $Z$ also. To improve the effective survey response rate, the

Table 2 Descriptive statistics and associated measures

\begin{tabular}{lcccccccc} 
Constructs & $\mathrm{M}$ & $\mathrm{SD}$ & 1 & 2 & 3 & 4 & 5 & 6 \\
\hline EAIP & 5.280 & 0.872 & 0.619 & & & & & \\
PIA & 5.275 & 0.838 & 0.244 & 0.527 & & & & \\
PIQ & 5.337 & 0.809 & 0.339 & 0.371 & 0.591 & & & \\
EC & 5.098 & 0.874 & 0.186 & 0.323 & 0.276 & 0.696 & & \\
PT & 4.908 & 0.898 & 0.202 & 0.234 & 0.270 & 0.398 & 0.647 & 0.733 \\
ES & 5.167 & 0.881 & 0.178 & 0.248 & 0.259 & 0.426 & 0.368 & 0.140 \\
SI & 3.637 & 0.956 & 0.003 & 0.017 & 0.032 & 0.040 & 0.051 & 0.726
\end{tabular}

Note(s): EAIP = Expertise of Amateur Information Publisher; PIA = Perceived Interactive Atmosphere; PIQ = Perceived Information Quality; $\mathrm{EC}=$ Expectation Confirmation; PT = Perceived Trust; ES = Experiential Satisfaction; $\mathrm{SI}=$ Switching Intentions 
research team used a face-to-face approach to randomly find those who have use UGC travel apps before. First, make sure the selected consumers were determined to be Generation Z, then explain the research purpose, finished the content of the questionnaire, and finally recovery of the questionnaire. The questionnaire in this study uses an anonymous method. The interviewee has questions and is unwilling to answer. We will not force them to comply with research ethics. The validity of high content is a necessary condition for the questionnaire survey in this study.

For the survey, qualified respondents among the invited participants were screened by asking them: (1) whether they were 18-25 years old and (2) in the past three months, whether they had used UGC travel apps to formulate a travel itinerary. Before responding to all items of the questionnaire, the participants were requested to answer a question about their preferred UGC travel apps as follows: "when you formulate a travel itinerary, which UGC travel Apps do you prefer to use?" The respondents were then asked to respond to the questions based on their experiences from their preferred travel app. Of the 387 returned questionnaires, 356 were valid and useable, giving a response rate of $91.9 \%$. The number of useable questionnaires was therefore above the minimum sample size of 345 as suggested by Hair et al. (2010) for factor analysis.

All the measurements of this study are collected from a single questionnaire, and this might result in the common method variance (CMV) problem (Podsakoff et al., 2003). In order to avoid this risk of $\mathrm{CMV}$, this study uses the Harmon's one factor test, which proposes that if the CMV problem exists, a dominant single factor might emerge (Podsakoff and Organ, 1986). The results show that no dominant factor emerges in the factor analysis using SPSS, and the greatest factor only explains $34.47 \%$ of the total variances, and thus this study is free of the CMV issue. For participants' demographic characteristics, more than half were female (53.7\%), and thus $46.3 \%$ were male. The average age of respondents was 21.3 years old. For travel frequency, most respondents traveled every 3 months to less than 6 months (49.7\%), followed by traveling every 6 months to less than 9 months (33.7\%).

\section{Empirical results}

The overall fit measures of the full model in structural equation modeling (SEM) indicate that the measurement model was considered acceptable according to the standards recommended by Hu and Bentler (1999). The $\chi^{2} /$ df ratio of less than $3.0\left(\chi^{2} / \mathrm{df}=2.17, p<0.001\right)$ was used as the common decision rule of an acceptable model fit. Other indicators of goodness of fit as recommended by Kline (1998) (RMSEA $=0.059$, GFI $=0.88$, AGFI $=0.85, \mathrm{IFI}=0.97$, $\mathrm{SRMR}=0.073$ ) indicate that the hypothesized model fit the empirical data well.

The detailed results of SEM are shown in Table 3. There are 10 hypotheses in total, 6 of the hypotheses are supported by statistics, and the exceptions are $\mathrm{H} 3, \mathrm{H} 4, \mathrm{H} 5$ and $\mathrm{H} 9$ (Table 3).

\section{Table 3 Standardized parameter estimates for the structural model}

\begin{tabular}{|c|c|c|c|}
\hline \multicolumn{2}{|c|}{ Paths } & \multirow{2}{*}{$\begin{array}{c}\begin{array}{c}\text { Path coefficient } \\
(T \text { value })\end{array} \\
0.32^{\star \star \star}(3.27)\end{array}$} & \multirow{2}{*}{$\frac{\text { Support }}{\text { Yes }}$} \\
\hline $\mathrm{H} 1$ & Expertise of amateur information publisher $\rightarrow$ perceived trust & & \\
\hline $\mathrm{H} 2$ & Perceived interactive atmosphere $\rightarrow$ perceived trust & $0.56^{\star \star \star}(5.70)$ & Yes \\
\hline $\mathrm{H} 3$ & $\begin{array}{l}\text { Expertise of amateur information publisher } \rightarrow \text { experiential } \\
\text { satisfaction }\end{array}$ & $-0.03(-0.23)$ & No \\
\hline $\mathrm{H} 4$ & Perceived interactive atmosphere $\rightarrow$ experiential satisfaction & $0.03(0.14)$ & No \\
\hline H5 & Perceived information quality $\rightarrow$ experiential satisfaction & $0.05(0.19)$ & No \\
\hline H6 & Perceived information quality $\rightarrow$ expectation confirmation & $0.83^{\star \star \star}(10.06)$ & Yes \\
\hline $\mathrm{H} 7$ & Expectation confirmation $\rightarrow$ experiential satisfaction & $0.49^{\star \star \star}(4.96)$ & Yes \\
\hline $\mathrm{H} 8$ & Perceived trust $\rightarrow$ experiential satisfaction & $0.33^{\star \star \star}(4.60)$ & Yes \\
\hline H9 & Perceived trust $\rightarrow$ switching intention & $0.12(1.16)$ & No \\
\hline $\mathrm{H} 10$ & Experiential satisfaction $\rightarrow$ switching intention & $-0.59^{\star \star \star}(-5.10)$ & Yes \\
\hline
\end{tabular}

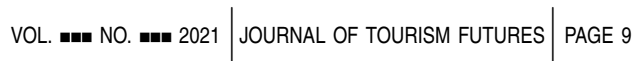


Research has found that experience satisfaction has no significant impact on amateur information publishers' professional knowledge, perceived interaction atmosphere and perceived information quality. From the interviews, we learned that Generation Z consumers will care about whether the publisher is professional when choosing a travel app. Ask friends about the quality of the information and the interactive atmosphere in the app. These are necessary conditions for choosing an app, so they do not. Because you have these characteristics, you will be satisfied. But they will greatly affect people's sense of trust, which also shows that Generation Z consumers are more convinced of their feelings about using app if it is too commercial, formal interaction (such as the card issued by the holiday company, etc.). Exquisite and flawless travel information will reduce consumers' trust in the platform. It shows that Generation Z consumers are called the generation that does not trust commercial advertising.

Furthermore, at first, the perceived information quality will enhance the consumer's expectation confirmation, and when the consumer's expectation confirmation is higher, it will also enhance the experience satisfaction of the app. When Generation Z consumers find that using platform information can reduce the uncertainty during the journey (for example, knowing that well-known stores in the travel destination have products that are not worth buying, the best travel time, etc.). Information publishers and other users or other users will be satisfied using the platform to discuss the fun or stories of travel. Second, perceived trust will increase consumer experience satisfaction. When consumers feel that the app is trustworthy, they think that they can plan their itinerary based on the content of the app, feel that the future described by the content is verifiable and increase their experience satisfaction when they travel. Therefore, consumers will often go to the application to view other users' shared content or provide opinions, which will make Generation Z consumers tend to stay in this UGC travel app and are unwilling to switch to other applications.

\section{Implications}

\subsection{Theoretical implications}

From a practical perspective, this study can provide further insight for UGC travel app's management to better understand how does the switching intention work in the proposed model and providing useful information to UGC travel app marketing managers who are designing the products and/or services in the UGC travel app. The findings of this study will provide UGC travel app's management with a clear understanding of influence perceived trust because these influence factors derive from the Generation Z consumers perspectives so that UGC travel app's management will know exactly the expertise of an amateur information publisher and perceived interactive atmosphere are necessary conditions for trusting UGC travel apps. In this study, we found that due to the authentic writing content and professional knowledge of amateur information publishers, consumers choose to trust the travel information provided by amateur information publishers, which will help increase consumer trust in the UGC travel APPs (Banerjee et al., 2017). Professionalism can be evaluated by the understanding of tourist destinations and the rationality of itinerary design (Goldsmith et al., 2000), but the perceived interactive atmosphere may vary from person to person (Chen et al., 2018), so managers can understand the differences between the online language of Generation Z consumers and other apps in order to provide consumers with a different way of interaction, managers can create unique interactive icons or online language based on their own corporate culture and the particularity of the app to consumers and use various games to increase interaction atmosphere.

The results show that the positive impact of expectation confirmation on experience satisfaction is significant (Hsu and Lin, 2015). Managers can design travel itineraries with different travel themes to ensure that consumers' expectations can be confirmed, thereby enhancing consumers' satisfaction with app experience. Furthermore, the positive impact of perceived information quality on expectation confirmation is significant (Chiu et al., 2005), and it can be seen that the perceived information quality plays a vital role in increasing expectation confirmation. Managers should set up consumer feedback or random inspection mechanisms for products/services to 
ensure that the information in the UGC travel application is correct and consistent with the travel destination, to ensure the effectiveness of the goods or services and help improve consumers' confirmation of expectations. In addition, the results of this research also provide valuable information about the complex relationship between the travel app field, expertise of amateur information publisher, perceived interactive atmosphere, perceived trust, experience satisfaction and conversion intentions for generational marketing. For example, the travel app management department should continue to work hard to increase the professionalism of UGC content and the emotional experience and novelty of consumers, which will help improve the satisfaction of the experience level and ultimately lead to a reduction in the willingness to switch (Kotler et al., 2003). Therefore, understanding the relationship between the seven structures in this study provides an opportunity for generational marketing. It needs to focus on providing the best perceptual interactive atmosphere, expertise of amateur information publisher, perceived information quality and expectation confirmation, and higher the perception of the perceived trust to improve the experience satisfaction of visitors and reduce their intention to transfer to other UGC travel apps.

\subsection{Managerial implications}

The study findings offer several managerial implications as follows.

First, the results reveal that perceived information quality has a positive influence on expectation confirmation (Hsu and Lin, 2015), which in turn positively leads to experiential satisfaction.

Offering a higher information quality of a travel app can narrow the gap between tourists' expectation and actual experience and thus enhance user satisfaction. Moreover, as the Generation Z consumers are more likely to be attracted by visual contents (Rezdy, 2018), travel app developers can leverage the role of visual effect and encourage users to share travel experiences in the form of pictures and videos of actual scenes, which can make information more reliable. For instance, they can learn from Tik Tok app by offering consumers real local landscape through creative, interesting and real images. For another example, they can add "Discovery Mode" to enable consumers to share travel experiences involving distinctive local scenic spots or food worthy of a try from other users. In this way, users would develop a strong sense of participation and experience and become motivated to offer more high-quality information.

Second, this study identifies that the positive influence of perceived interactive atmosphere on perceived trust is significant (Shan and Lu, 2010). The Generation Z pay attention to social interaction, look forward to expanding their social networks in virtual communities and alleviate their loneliness by communicating with netizens who share much with them (Rezdy, 2018). Hence, travel app developers and operators can learn from Mafengwo app, which answers the questions raised by users through "mutual assistance" and enables users to share travel experiences, thus enhancing users' sense of belonging to a community and promoting their viscosity (e.g. let consumers want to use, continue to use, recommend the travel app to others and are willing to participate in activities in the travel app and interact with other consumers and measure their travel plans or purchasing choices with confidence and efficiency).

Third, the finding confirms that the positive effects of the expertise of an amateur information publisher on perceived trust are significant (Banerjee et al., 2017).

UGC is a marketing method of the company that allows consumers to actively generate feedback on the brand (Assaker, 2020). As the Generation Z consumers place the least trust on traditional advertising and marketing, they tend to show more trust on users who are familiar with a targeted tourist destination than an advertising star and an employed professional. Users can be tourists who have traveled to the target scenic spot or the locals. Therefore, travel developers can learn from Qyer app by adding a mechanism granting such honorary titles as "Senior User in Region and Interest", "Q\&A Trailblazer" and "Destination Player". In this way, tourists or locals will be motivated to share the most comprehensive, genuine and popular information to win the honorary titles. 
If a user finishes the accreditation, then his/her profile and homepage will be decorated with an accreditation mark that can tell other users of their professionalism.

\section{Limitations and future research}

There are several limitations to this study. First, the variables in this study focus on the expertise of an information publisher, interactive atmosphere, perceived trust, information quality, expectation confirmation, experiential satisfaction and switching intentions from the perspective of Generation Z consumers who use UGC travel apps. Future studies can try to add or modify more variables to expand the scope of this study and enhance accuracy.

Second, this study conducted a random sampling of consumers who had used UGC travel apps. However, most researchers have not fully understood the reasons why consumers switch from one travel app to another. In this regard, it is suggested that future studies cooperate with travel app organizations to obtain data on consumers' switching experiences and divide them into multiand single-branded travel app users (Woodham et al. , 2017). This can help us understand how to effectively increase perceived information quality and enhance expectation confirmation, which in turn can reduce perceptions of switching intentions.

Third, other important variables have not been considered in this study.

This research has discussed how to reduce the switching intention of the Generation Z consumers from the perspective of their demand for travel apps, but according to their values, brand matters most in social interaction. Nevertheless, brand was not explored herein. Future studies can take love of a brand into account, which is a new concept for the existing literature on customer behavior (Thomson et al., 2005; Yasin and Shamim, 2013). Brand experience is another concept worth exploring, and many studies have agreed that it is highly useful (Yasin and Shamim, 2013), because knowledge of how consumers experience brands will deepen our understanding of the loyalty of the Generation Z consumers and help enterprises improve their marketing strategies.

\section{Conclusions}

Despite the limitations of this study, the following contributions can still be made. First is the substantial significance of this study to explore how the low-loyalty Generation Z enters the tourism market and how to reduce their switch intention. Second, to gain the favor and trust of Generation Z consumers, travel apps should have expertise from amateur information publishers, perceived interactive atmosphere and perceived information quality. Third, UGC Travel app can use expectation confirmation, perceived information quality and perceived trust to enhance consumers' benefits and reduce customer's perceived price, thereby enhancing customer value and helping to improve the degrees of users' satisfaction with UGC travel app's experience. Fourth, experience satisfaction is more helpful than perceived trust to reduce Generation $Z$ consumers' switch intention to other UGC travel app.

\section{References}

Akter, S., Ray, P. and D'Ambra, J. (2013), "Continuance of mHealth services at the bottom of the pyramid: the roles of service quality and trust", Electronic Markets, Vol. 23 No. 1, pp. 29-47.

Almahamid, S., Mcadams, A.C., Al Kalaldeh, T. and Mo'taz, A.S.E. (2010), "The relationship between perceived usefulness, perceived ease of use, perceived information quality, and intention to use e-government", Journal of Theoretical and Applied Information Technology, Vol. 11, pp. 30-44.

Assaker, G. (2020), "Age and gender differences in online travel reviews and user-generated-content (UGC) adoption: extending the technology acceptance model (TAM) with credibility theory", Journal of Hospitality Marketing and Management, Vol. 29 No. 4, pp. 428-449.

Ayeh, J.K., Au, N. and Law, R. (2016), "Investigating cross-national heterogeneity in the adoption of online hotel reviews", International Journal of Hospitality Management, Vol. 55, pp. 142-153.

PAGE 12 JOURNAL OF TOURISM FUTURES $\mid$ VOL. $\mathbf{m}$ NO. $\mathbf{m} 2021$ 
Bae, S. and Lee, T. (2011), "Gender differences in consumers' perception of online consumer reviews", Electronic Commerce Research, Vol. 11 No. 2, pp. 201-214.

Bagozzi, R.P. and Yi, Y. (1988), "On the evaluation of structural equation models", Journal of the Academy of Marketing Science, Vol. 16, pp. 74-94.

Bahtar, A.Z. and Muda, M. (2016), "The impact of User-Generated Content (UGC) on product reviews towards online purchasing-A conceptual framework", Procedia Economics and Finance, Vol. 37, pp. 337-342.

Banerjee, S., Bhattacharyya, S. and Bose, I. (2017), "Whose online reviews to trust? Understanding reviewer trustworthiness and its impact on business", Decision Support Systems, Vol. 96, pp. 17-26.

Bansal, H.S., Taylor, S.F. and StJames, Y. (2005), "Migrating" to new service providers: toward a unifying framework of consumers' switching behaviors", Journal of the Academy of Marketing Science, Vol. 33 No. 1, pp. 96-115.

Bart, Y., Shankar, V., Sultan, F. and Urban, G.L. (2005), "Are the drivers and role of online trust the same for all web sites and consumers? A large-scale exploratory empirical study", Journal of Marketing, Vol. 69, pp. 133-152.

Bedford, D.W. (2005), Empirical Investigation of the Acceptance and Intended Use of Mobile Commerce: Location, Personal Privacy and Trust, Mississippi State University, MS.

Bhattacherjee, A. (2001), "Understanding information systems continuance an expectation-confirmation model”, MIS Quarterly, Vol. 25 No. 3, pp. 351-370.

Bricci, L. Fragata, A. and Antunes, J. (2016), "The effects of trust, commitment and satisfaction on customer loyalty in the distribution sector", Journal of Economics, Business and Management, Vol. 4 No. 2, pp. 173-177.

Brown, T.A. (2006), Confirmatory Factor Analysis for Applied Research, Guilford, New York.

Chen, Y., He, Y.S. and Jin, S. (2018), "Can community climate lead to impulse buying? A study of the effect and mechanism of different community climate dimensions", Journal of Business Economics, Vol. 4, pp. 59-69.

Cheng, Y.M. (2014), "Extending the expectation-confirmation model with quality and flow to explore nurses' continued blended e-learning intention", Information Technology and People, Vol. 27 No. 3, pp. 230-258.

Chiu, C.M., Hsu, M.H., Sun, S.Y., Lin, T.C. and Sun, P.C. (2005), "Usability, quality, value and e-learning continuance decisions", Computers and Education, Vol. 45 No. 4, pp. 399-416.

Churchill, G.A. Jr (1979), "A paradigm for developing better measures of marketing constructs", Journal of Marketing Research, Vol. 16 No. 1, pp. 64-73.

Corbisiero, F. and Ruspini, E. (2018), "Millennials and Generation Z: challenges and future perspectives for international tourism", Journal of Tourism Futures, Vol. 4 No. 1, pp. 3-104.

Doney, P.M. and Cannon, J.P. (1997), "An examination of the nature of trust in buyer-seller relationships", Journal of Marketing, Vol. 61 No. 2, pp. 35-51.

Filieri, R., McLeay, F. and Tsui, B. (2017), "Antecedents of travellers' satisfaction and purchase intention from social commerce websites", in Information and Communication Technologies in Tourism 2017, Springer, Cham, pp. 517-528.

Fornell, C. and Larcker, D.F. (1981), "Evaluating structural equation models with unobservable variables and measurement error", Journal of Marketing Research, Vol. 18 No. 1, pp. 39-50.

Gefen, D., Karahanna, E. and Straub, D.W. (2003), "Trust and TAM in online shopping: an integrated model”, MIS Quarterly, Vol. 27 No. 1, pp. 51-90.

Goldsmith, R.E., Lafferty, B.A. and Newell, S.J. (2000), "The impact of corporate credibility and celebrity credibility on consumer reaction to advertisements and brands", Journal of Advertising, Vol. 29 No. 3, pp. 43-54.

Hair, J.F., Anderson, R.E., Tatham, R.L. and Black, W.C. (1998), Multivariate Data Analysis, Prentice Hall International, Englewood, CA.

Hair, J.F.J., Black, W.C., Babin, B.J. and Anderson, R.E. (2010), Multivariate Data Analysis: A Global Perspective, 7th ed., Pearson Education, Upper Saddle River, NJ.

Hovland, C.I., Janis, I.L. and Kelley, H.H. (1953), Communication and Persuasion, Yale University Press, New Haven, CT. 
Hsu, C.L. and Lin, J.C.C. (2015), "What drives purchase intention for paid mobile apps? - an expectation confirmation model with perceived value", Electronic Commerce Research and Applications, Vol. 14 No. 1, pp. 46-57.

Hu, L.T. and Bentler, P.M. (1999), "Cutoff criteria for fit indexes in covariance structure analysis: conventional criteria versus new alternatives", Structural Equation Modeling: A Multidisciplinary Journal, Vol. 6 No. 1, pp. 1-55.

Izogo, E.E. (2016), "Should relationship quality be measured as a disaggregated or a composite construct?", Management Research Review, Vol. 39 No. 1, pp. 115-131.

Jin, S.V. and Phua, J. (2016), "Making reservations online: the impact of consumer-written and systemaggregated user-generated content (UGC) in travel booking websites on consumers' behavioral intentions", Journal of Travel and Tourism Marketing, Vol. 33 No. 1, pp. 101-117.

Joo, S. and Choi, N. (2016), “Understanding users' continuance intention to use online library resources based on an extended expectation-confirmation model", The Electronic Library, Vol. 34 No. 4, pp. 554-571.

Kantar and Tencent (2018), “2018 China's Gen Z, White Paper”, available at: https://socialone.com.cn/Zgen-consumption-2018/.

Kao, Y.F., Huang, L.S. and Wu, C.H. (2008), "Effects of theatrical elements on experiential quality and loyalty intentions for theme parks", Asia Pacific Journal of Tourism Research, Vol. 13 No. 2, pp. 163-174.

Karamian, H., Nadoushan, M.A. and Nadoushan, A.A. (2015), "Do social media marketing activities increase brand equity", International Journal of Economy, Management and Social Sciences, Vol. 4 No. 3, pp. 362-365.

Keaveney, S.M. (1995), "Customer switching behavior in service industries: an exploratory study", Journal of Marketing, Vol. 59 No. 2, pp. 71-82.

Khalilullah, M.Z.G. (2013), "The influence of image and trust on satisfaction and its impact towards Loyalty of Bank Syariah Mandiri”, working paper, Economics Faculty, University of Syiah Kuala, Aceh.

Kim, Y.A. and Ahmad, M.A. (2013), "Trust, distrust and lack of confidence of users in online social mediasharing communities”, Knowledge-Based Systems, Vol. 37, pp. 438-450.

Kim, I. and Kim, J.J. (2017), "Older adults' parasocial interaction formation process in the context of travel websites: the moderating role of parent-child geographic proximity", Tourism Management, Vol. 63, pp. 399-416.

Kim, S.L., Teo, T.S., Bhattacherjee, A. and Nam, K. (2017), "IS auditor characteristics, audit process variables, and IS audit satisfaction: an empirical study in South Korea", Information Systems Frontiers, Vol. 19 No. 3, pp. 577-591.

Kline, R.B. (1998), Principles and Practice of Structural Equation Modeling, Guilford Press, New York, NY.

Koo, C., Wati, Y., Park, K. and Lim, M.K. (2011), "Website quality, expectation, confirmation, and end user satisfaction: the knowledge-intensive website of the Korean National Cancer Information Center", Journal of Medical Internet Research, Vol. 13 No. 4, p. e81.

Kotler, P., Bowen, J. and Makens, J. (2003), Marketing for Hospitality and Tourism, 3rd ed., Prentice Hall, Englewood Cliffs, NJ.

Laumer, S. Maier, C. and Weitzel, T. (2017), "Information quality, user satisfaction, and the manifestation of workarounds: a qualitative and quantitative study of enterprise content management system users", European Journal of Information Systems, Vol. 26 No. 4, pp. 333-360.

Lee, B.G., Lee, Y. and Kim, S.J. (2011), "What is the most important factor in switching blogs?", International Journal of Web Based Communities, Vol. 7 No. 1, pp. 83-97.

Li, D., Browne, G.J. and Wetherbe, J.C. (2007), "Online consumers' switching behavior: a buyer-seller relationship perspective", Journal of Electronic Commerce in Organizations, Vol. 5 No. 1, pp. 30-42.

Liang, L.J., Choi, H.C. and Joppe, M. (2018), "Exploring the relationship between satisfaction, trust and switching intention, repurchase intention in the context of Airbnb", International Journal of Hospitality Management, Vol. 69, pp. 41-48.

Mayer, R.C., Davis, J.H. and Schoorman, F.D. (1995), "An integrative model of organizational trust", Academy of Management Review, Vol. 20 No. 3, pp. 709-734.

PAGE $14 \mid$ JOURNAL OF TOURISM FUTURES $\mid$ VOL. $\mathbf{m}$ NO. $\mathbf{m} 2021$ 
McKinney, V., Yoon, K. and Zahedi, F.M. (2002), "The measurement of web-customer satisfaction: an expectation and disconfirmation approach", Information Systems Research, Vol. 13 No. 3, pp. 296-315.

McKnight, D.H., Choudhury, V. and Kacmar, C. (2002), "The impact of initial consumer trust on intentions to transact with a web site a trust building model", The Journal of Strategic Information Systems, Vol. 11 Nos 3-4, pp. 297-323.

Mir, I.A. and Ur Rehman, K. (2013), "Factors affecting consumer attitudes and intentions toward usergenerated product content on YouTube", Management and Marketing, Vol. 8 No. 4, pp. 637-654.

Netemeyer, R.G., Bearden, W.O. and Teel, J.E. (1992), "Consumer susceptibility to interpersonal influence and attributional sensitivity", Psychology and Marketing, Vol. 9 No. 5, pp. 379-394.

Nunnally, J.C. (1978), Psychometric Theory, 2nd ed., McGraw-Hill, New York, NY.

Oliver, R.L. (1980), "A cognitive model of the antecedents ang consequences of satisfaction decisions", Journal of Marketing Research, Vol. 17 No. 4, pp. 460-469.

Özkan, P.M. (2017), "Generation Z-the global market's new consumers-and their consumption habits: Generation Z consumption scale", European Journal of Multidisciplinary Studies, Vol. 2 No. 5, pp. 150-157.

Park, S., Tussyadiah, I.P. and Zhang, Y. (2016), "Assessment of perceived risk in mobile travel booking", in Information and Communication Technologies in Tourism 2016, Springer, Cham, pp. 467-480.

Pinto, N.P., Gomes, D.D.O., Cavalcante, F., Mendes, G.A. and Sales, R.K.L. (2015), "The influence of social networks on consumers' buying decision process-a study of tourism products", Asian Journal of Business and Management Sciences, Vol. 4 No. 3, pp. 1-10.

Podsakoff, P.M. and Organ, D.W. (1986), "Self-reports in organizational research: problems and prospects", Journal of Management, Vol. 12 No. 4, pp. 531-544.

Podsakoff, P.M., MacKenzie, S.B., Lee, J.-Y. and Podsakoff, N.P. (2003), "Common method biases in behavioral research: a critical review of the literature and recommended remedies", Journal of Applied Psychology, Vol. 88 No. 5, pp. 879-903.

Rezdy (2018), "Generation Z: an in-depth look into the travel segment", available at: https://www.rezdy.com/ blog/generation-z-depth-look-travel-segment-infographic/.

Robinson, V.M. and Schänzel, H.A. (2019), "A tourism inflex: Generation Z travel experiences", Journal of Tourism Futures, Vol. 5 No. 2, pp. 127-141.

Shan, C. and Lu, Y. (2010), "A study on the effects of positive and negative online reviews on consumers' initial trust in C2C vendors", Library and Information Service, Vol. 54 No. 12, pp. 136-140.

Shankar, V., Urban, G.L. and Sultan, F. (2002), "Online trust: a stakeholder perspective, concepts, implications, and future directions", The Journal of Strategic Information Systems, Vol. 11 Nos 3-4, pp. 325-344.

Shatto, B. and Erwin, K. (2016), "Moving on from millennials: preparing for generation Z", The Journal of Continuing Education in Nursing, Vol. 47 No. 6, pp. 253-254.

Skift (2017), "U.S millennials travel the most but Gen Z is on the rise", 2017, available at: https://skift.com/ 2017/10/02/u-s-millennials-travel-the-most-but-gen-z-is-on-the-rise/.

Szymanski, D.M. and Hise, R.T. (2000), "E-satisfaction: an initial examination”, Journal of Retailing, Vol. 76 No. 3, pp. 309-322.

Thomson, M., Maclnnis, D.J. and Park, C.W. (2005), "The ties that bind: measurement the strength of consumers' emotional attachments to brands", Journal of Consumer Psychology, Vol. 15 No. 1, pp. 77-91.

Turban, E. and Gehrke, D. (2000), "Determinants of e-commerce website", Human Systems Management, Vol. 19 No. 2, pp. 111-120.

Ukpabi, D.C. and Karjaluoto, H. (2018), "What drives travelers' adoption of user-generated content? A literature review", Tourism Management Perspectives, Vol. 28, pp. 251-273.

Uotila, T. and Melkas, H. (2008), "Complex knowledge conversion processes and information quality in regional innovation networks", Knowledge and Process Management, Vol. 15 No. 4, pp. 224-234.

Verhellen, Y., Dens, N. and De Pelsmacker, P. (2013), "Consumer responses to brands placed in Youtube movies: the effect of prominence and endorser expertise", Journal of Electronic Commerce Research, Vol. 14 No. 4, pp. 287-303. 
Veríssimo, M. and Costa, C. (2018), "Do hostels play a role in pleasing Millennial travellers? The Portuguese case", Journal of Tourism Futures, Vol. 4 No. 1, pp. 57-68.

Wang, X. and Li, L. (2015), "The influence of interactive utility of user- generated content on consumer brand attitude-Moderating effect of the susceptibility to interpersonal influence", Journal of Modern Information, Vol. 35 No. 7 , pp. 24-28.

Wavemaker (2017), "China Generation Z research report", available at: http://www.madisonboom.com/ 2017/09/21/the-report-of-generation-z-by-mec/ (accessed 22 April 2020).

Wilkinson, G.L., Bennett, L.T. and Oliver, K.M. (1997), "Evaluation criteria and indicators of quality for internet resources", Special Issue: Web-Based Learning, Vol. 37 No. 3, pp. 52-59.

Woodham, O.P., Hamilton, M.L. and Leak, R.L. (2017), "I know what I like, I like what I know: how breadth of brand experience and cognitive effort influence brand switching", Journal of Marketing Theory and Practice, Vol. 25 No. 2, pp. 141-159.

Wu, H. and Xiao, T. (2017), "Study of user based on sense of community and value: cases from online travel community”, Human Geography, Vol. 32 No. 4, pp. 155-160.

Wu, H.C., Li, M.Y. and Li, T. (2018a), "A study of experiential quality, experiential value, experiential satisfaction, theme park image, and revisit intention", Journal of Hospitality and Tourism Research, Vol. 42 No. 1, pp. 26-73.

Wu, H.C., Wei, C.F., Tseng, L.Y. and Cheng, C.C. (2018b), “What drives green brand switching behavior?”, Marketing Intelligence and Planning, Vol. 36 No. 6, pp. 694-708.

Xiang, Z., Magnini, V.P. and Fesenmaier, D.R. (2015), "Information technology and consumer behavior in travel and tourism: insights from travel planning using the internet", Journal of Retailing and Consumer Services, Vol. 22, pp. 244-249.

Yang, R. (2017), "Dimensions exploration and scale development of customer to customer interaction based on virtual brand community", Chinese Journal of Management, Vol. 14 No. 1, pp. 111-121.

Yasin, M. and Shamim, A. (2013), "Brand love: mediating role in purchase intentions and word-of-mouth", IOSR Journal of Business and Management, Vol. 7 No. 2, pp. 101-109.

Zeithaml, V.A., Berry, L.L. and Parasuraman, A. (1996), "The behavioral consequences of service quality", Journal of Marketing, Vol. 60 No. 2, pp. 31-46.

\section{Further reading}

Gupta, A., Dogra, N. and George, B. (2018), "What determines tourist adoption of smartphone apps?: an analysis based on the UTAUT-2 framework", Journal of Hospitality and Tourism Technology, Vol. 9 No. 1, pp. 50-64.

\section{Corresponding author}

Jung-Hsiang Chang can be contacted at: tonycjs@gmail.com

For instructions on how to order reprints of this article, please visit our website: www.emeraldgrouppublishing.com/licensing/reprints.htm Or contact us for further details: permissions@emeraldinsight.com 